\title{
Impact of Dairy and Sweetened Beverage Consumption on Diet and Weight of a Multiethnic Population of Head Start Mothers
}

CAROL E. O'NEIL, PhD, RD,

Ann Peltier professor of dietetics, Louisiana State University AgCenter, Baton Rouge

THERESA A. NICKLAS, DrPH,

Professor, Children's Nutrition Research Center, Department of Pediatrics, Baylor College of Medicine, Houston, TX

YAN LIU, MS, and

Statistician, Children's Nutrition Research Center, Department of Pediatrics, Baylor College of Medicine, Houston, TX

FRANK A. FRANKLIN, MD, PhD, MPH

Professor and chair, University of Alabama at Birmingham, Department of Maternal and Child Health, University of Alabama at Birmingham School of Public Health, Birmingham

\section{Abstract}

\begin{abstract}
Mothers with children in Head Start play a critical role in providing healthful diets and modeling good dietary behaviors to their children, but there is little information available on their diet, especially on beverage consumption. The objective of this study was to assess the association of milk and sweetened beverage consumption with nutrient intake, dietary adequacy, and weight of a multiethnic population of Head Start mothers. Using a cross-sectional, secondary analysis, AfricanAmerican (43\%), Hispanic (33\%), and white (24\%) women ( $\mathrm{n}=609)$ were divided into four beverage consumption groups: high milk/low sweetened beverage, high milk/high sweetened beverage, low milk/low sweetened beverage, and low milk/high sweetened beverage. Nutrient intake was determined by averaging 24-hour dietary recalls from 3 nonconsecutive days. Dietary adequacy was determined with the Mean Adequacy Ratio. Mean body mass index for the four beverage consumption groups was compared; there were no differences among the groups (overall mean \pm standard error $=30.8 \pm 0.3$ ). Women in the high milk/low sweetened beverage group had higher mean intakes of vitamins A, D, and B-6; riboflavin; thiamin; folate; phosphorus; calcium; iron; magnesium; and potassium $(P<0.0125$ for all $)$ when compared with the other beverage consumption groups. Mean Adequacy Ratio was highest in the high milk/low sweetened beverage $(71.8 \pm 0.8)$ and lowest in the low milk/high sweetened beverage $(58.4 \pm 0.8)$ consumption groups $(P<0.0125)$. Women in the high milk/low sweetened beverage group consumed more nutrient-dense foods. Overall consumption of milk was low. Consumption of high milk/low sweetened beverage was associated with improved nutrient intake, including the shortfall nutrients, ie, calcium, potassium, magnesium, and vitamin A.
\end{abstract}

Address correspondence to: Theresa A. Nicklas, DrPH, Children's Nutrition Research Center, Department of Pediatrics, Baylor College of Medicine, 1100 Bates Ave, Houston, TX 77030.tnicklas@bcm.tmc.edu.

The contents of this publication do not necessarily reflect the views or policies of the USDA, nor does the mention of trade names, commercial products, or organizations imply endorsement from the US government. None of the sponsors had a role in the design and conduct of the study; the collection, management, analysis, and interpretation of the data; or the preparation and approval of the manuscript.

Funding Disclosure: Dairy Management, Inc. 
Head Start is a national program designed to promote school-readiness by enhancing social and cognitive development of children from birth to 5 years of age who are below the poverty line through educational, health, nutrition, and social services (1). Mothers play a vital role in determining food availability (2), encouraging specific eating practices (3), and modeling dietary behaviors $(4,5)$ for their children. There are few published articles about the diets of Head Start mothers $(6,7)$; one study conducted in mothers and toddlers in Early Head Start suggested that poor diet quality of the mother was associated with poor diet quality in the child (7). Virtually nothing is available on the impact that beverage intake has on overall nutrient intake and diet quality in low-income mothers. Mothers with higher calcium intakes tended to drink more milk and fewer soft drinks; these mothers had daughters who tended to drink more milk and fewer soft drinks and to have higher calcium intakes, suggesting mothers have a positive influence on the diets of young children (8). Individuals with more healthful beverage choices appear to have overall better food options.

Low-income women tend to have diets that compromise health (9-11). Poor food choices increase the likelihood of dietary inadequacies, thereby potentially adversely affecting health status (9-11). Low-income females are also more likely than high-income females to report having poorer overall health or chronic disease (12-14), and obesity rates are high (15-17).

Data from the National Health and Nutrition Examination Survey 2003-2004 showed that $28.9 \%$ and $38.8 \%$ of females 20 to 39 years of age and 40 to 59 years of age, respectively, were obese (18). African-American females had a higher prevalence of obesity than whites or Mexican Americans (18). These figures have increased dramatically from 1971 to 1974, when the prevalence of obesity for women in those age groups was $11.2 \%$ and $19.7 \%$, respectively. There has been a concomitant shift in beverage intake $(19,20)$; and beverages, especially sweetened beverages, have come under scrutiny as a contributor to overweight/obesity (21). Beverage intake by women 20 to 39 years of age and 40 to 59 years of age provides $19 \%$ and $15 \%$, respectively, of daily energy intake, with no differences in total energy intake from beverages across ethnic groups (19). In the past 30 years, there has been a shift away from nutrient-dense beverages, like milk, to higher-energy, nutrient-poor beverages, like regular soft drinks $(19,20)$, which are the single largest source of energy in the diet of Americans (22).

In some studies, sweetened beverage consumption has been associated with overall poor nutrient intake (23-27), and it has been argued that sweetened beverages "displace" milk in the diet $(25,27)$. Other studies have failed to show an effect of sweetened beverage consumption on nutrient intake or diet quality $(28,29)$. Sweetened beverage consumption has been linked to adverse health outcomes (30); however, the role of sweetened beverage consumption in overweight in adults is unclear (30-34).

Milk consumption improves overall diet quality $(35,36)$. Increasing quartiles of milk-product intake were associated with increased intakes of the micronutrients except vitamin C (37). Intake of calcium, potassium, magnesium, zinc, vitamins $\mathrm{A}$ and $\mathrm{D}$, riboflavin, and folate were improved with milk consumption $(38,39)$. Calcium, potassium, magnesium, and vitamin A have been identified as shortfall nutrients in the diets of adults (40). Epidemiologic (41-44) and intervention (44) studies have suggested that dairy foods have favorable effects on body weight and composition. The purpose of this study was to assess the impact of milk and sweetened beverage consumption patterns on nutrient and food group intake, dietary adequacy, and weight of Head Start mothers. 


\section{METHODS}

\section{Subjects}

This study was a secondary analysis of data collected for a cross-sectional assessment of mother-child dyads in Head Start families recruited from 57 Head Start centers in three geographical areas in northern rural Alabama, northern urban Alabama, and southeastern urban Texas. These sites were selected because they serve ethnically diverse populations and lowincome groups in the South are understudied. The purpose of the original study was to determine and compare facilitators and barriers to fruit and vegetable intakes in preschool children from three race/ethnic groups: African American, Hispanic, and white. Inclusion criteria for this study were being a nonpregnant female 20 to 50 years of age, having a child enrolled in Head Start in his or her first year of participation, having an income at or below $100 \%$ of the poverty index, and self-identifying race/ethnicity as African American, Hispanic, or white. The response rate was $80 \%$; however, because those participating in Head Start programs are a homogeneous population, there was no difference between respondents and nonrespondents. Ethnic breakdown of the study population reflected the racial/ethnic distribution of the Head Start districts in Houston and Alabama. An incentive of $\$ 35$ and a coupon booklet were provided. Only those who completed three 24-hour recalls $(n=620)$ were initially included. Excluded from this group were those with reported mean energy intakes $<600$ calories $(n=6)$ or $>4,000$ calories $(n=4)(45)$. Another subject was deleted after reporting consuming 39 servings of sweetened beverages. The final sample size was 609 .

\section{Study Procedures}

This study was approved by the Institutional Review Boards of Baylor College of Medicine and University of Alabama at Birmingham and written informed consent was obtained from all participants. During a 2-week period, data collectors trained and certified in dietary and anthropometric assessments obtained heights, weights, and demographic data. Using the multiple-pass method, three 24-hour dietary recalls ( 1 weekend day and 2 nonconsecutive weekdays; announced previously) were collected (46). Food models helped participants describe portion sizes (47). Heights and weights were measured twice on each participant without shoes and dressed in light clothing (48). Weight was measured to the closest $0.1 \mathrm{~kg}$ on a digital platform scale accurate to $500 \mathrm{~kg}$ within $\pm 0.05 \mathrm{~kg}$ (Befour Model PS-6600, Saukville, WI). Height was measured to the closest $0.1 \mathrm{~cm}$ using the Shorr Adult Height Measuring Board (Shorr Productions Growth Unlimited, Olney, MD). Body mass index (BMI) was calculated as $\mathrm{kg} / \mathrm{m}^{2}$.

\section{Diet Analysis}

Dietary intake data were analyzed using Nutrient Data System for Research software (version 5.0_35, 2005, University of Minnesota, Minneapolis). Three days of dietary intakes were averaged to improve estimates of dietary intakes. Nutrient intakes from foods and beverages were determined. Added sugars were defined as all sugars eaten separately or used as ingredients in processed or prepared foods (49). Percent energy from protein, carbohydrates, total fat, saturated fatty acids, and total and added sugars was also calculated.

Mean Adequacy Ratio (MAR) of eight key nutrients was calculated as an indicator of overall dietary adequacy (6). Indicator nutrients for the MAR were good markers for consumption of fruit, vegetables, milk, whole grains, dietary fiber, vitamins A and C, folate, calcium, iron, zinc, and potassium. The nutrient adequacy ratio, or percentage of the Recommended Dietary Allowances consumed, was calculated for each nutrient and the resulting value truncated at 100 before averaging, so those consuming large amounts of food were not unfairly advantaged. MAR equals the sum of nutrient adequacy ratios divided by the number of nutrients considered 
$(6,50)$. A score of 85 was selected as the cut-point for adequacy (6) and was close to the Estimated Adequate Intake for most nutrients.

Mean intakes of foods and beverages were reported as the five main food groups: grains, fruit, vegetables, dairy, and meats. Legumes were placed in the vegetable group, and nuts were placed in the meat group (51). Food groups and serving sizes were consistent with the Nutrient Data System definitions (52).

\section{Data Analysis}

Statistical analyses were conducted using the Statistical Analysis Software (version 9.1.3., 2006, SAS Institute Inc, Cary, NC). BMI was calculated as kg/m² (53). Mean 3-day, 24-hour intakes of milk and sweetened beverage were categorized into four consumption patterns: low milk/low sweetened beverages; low milk/high sweetened beverages; high milk/low sweetened beverages; and high milk/high sweetened beverages. Low milk/high milk categories were defined: $\leq$ or $>$ median $(0.312)$ of total milk servings per day, respectively. Low sweetened beverages/high sweetened beverage categories were defined as: $\leq$ or $>$ median (1.354) of sweetened beverage servings per day, respectively. "Milk" included all forms of milk. Sweetened beverages included soft drinks, fruit drinks/ades, sweetened tea or coffee, and sweetened water.

Mean \pm standard error and frequency distributions of participant characteristics were calculated. Analysis of variance was conducted for detecting differences in milk/sweetened beverage consumption groups for continuous variables and $\chi^{2}$ was used for categorical variables. A $P$ value $<0.05$ was considered statistically significant. Analysis of covariance was used for calculating the least-squares means of dependent variables using the SAS procedure PROC GLM. Covariates were age, ethnicity, and energy intake. Because multiple comparisons were done in the post hoc analysis, the Bonferroni correction was used to decrease the probability of a type I error; the effective probability level was $<0.0125$.

\section{RESULTS \\ Demographics}

Demographic and BMI data by milk and sweetened beverage consumption pattern groups are shown in Table 1. The low milk/high sweetened beverages and the high milk/low sweetened beverages each comprised $27.9 \%$ of the population; and the low milk/low sweetened beverages and high milk/high sweetened beverages comprised $22.0 \%$ and $22.2 \%$, respectively. The sample distribution by location and race/ethnicity was 33\% Hispanic from Texas, $43 \%$ African American from Texas and Alabama, and 24\% white from Alabama. Hispanics had the highest percentages in the high milk groups and African Americans had the highest percentages in a low-milk group, regardless of sweetened beverage consumption. Mean adjusted BMI was 30.8 \pm 0.3 . There was no difference in mean BMI among the milk/sweetened beverage consumption groups.

\section{Nutritional Impact of Milk and Sweetened Beverages Consumption-Energy, MAR, and Micronutrients}

Energy, MAR, and micronutrient intakes by milk and sweetened beverage consumption groups are shown in Table 2. Women in the low milk/low sweetened beverage group had the lowest energy intake/basal metabolic rate (0.8), whereas women in the high milk/high sweetened beverage group had the highest $(1.4)(P<0.05)$. Mean MAR scores for dietary adequacy were highest among those in the high milk/low sweetened beverage group and lowest in the low milk/high sweetened beverage group $(P<0.05)$. Women in the high milk/low sweetened beverage groups had significantly higher mean intakes of vitamins A, D, and B-6; riboflavin; 
thiamin; folate; phosphorus; calcium; iron; magnesium; and potassium than women in the other beverage consumption groups $(P<0.05)$. Women in the low milk/high sweetened beverage group had the lowest mean intakes of vitamin B-6, thiamin, folate, phosphorus, calcium, iron, potassium, and magnesium, when compared with the other beverage consumption groups $(P<0.05)$.

\section{Nutritional Impact of Milk and Sweetened Beverage Consumption-Macronutrients}

Macronutrient intakes by milk and sweetened beverage consumption groups are also shown in Table 2. Mean total fat intake in grams and percent of energy was highest in the low milk/low sweetened beverage group, and was lowest in the high milk/high sweetened beverage group. Mean saturated fatty acids and monounsaturated fatty acid intakes were lowest in the high milk/ high sweetened beverage group. Dietary fiber was higher in both groups consuming low sweetened beverages than in either of the groups consuming high sweetened beverages. Intake of total and added sugars and percent of energy from total and added sugars was higher in the high sweetened beverage consumption groups when compared with the lower sweetened beverage consumption groups.

\section{Food Group Consumption}

Food group consumption data are presented in Table 3. The high milk/low sweetened beverage group consumed more servings of ready-to-eat cereals (RTEC), fruit, dark green and deep yellow vegetables, and dairy food, including fluid milk, than the other beverage consumption groups. The high milk/low sweetened beverage group also consumed more servings of whole grains, fruit, milk, and water, and fewer servings of luncheon meats than the low milk/high sweetened beverage consumption group. Both low sweetened beverage groups drank significantly more water than the two high sweetened beverage consumption groups $(P<0.05)$.

\section{DISCUSSION}

This study showed that mean nutrient intake and diet adequacy was highest in the high milk/ low sweetened beverage consumption group and lowest in the low milk/high sweetened beverage consumption group. The high milk/low sweetened beverage group tended to make more healthful food choices than those in the other beverage consumption groups. This finding has been unreported in populations of Head Start mothers; however, it does complement a recent study (54), which showed that adults with more healthful dietary patterns had more healthful beverage patterns. These two studies suggest that beverages, like foods, should not be studied in isolation because individuals can have different beverage consumption patterns.

This study did not show an association among milk/sweetened beverage consumption groups and weight. Historically, low-income women have been shown to be overweight in comparison with their higher-income peers (15-17); however, more recently this gap has disappeared as obesity has become more prevalent in the general population (55). Why low-income women tend to be obese is not clear, but episodic eating patterns $(10,11,15)$, high energy-dense food choices $(10,11)$, and disordered eating $(16,10,11,56)$ may play a role.

Milk consumption was low, even in the high milk/low sweetened beverage group. Median intake of the population, which served as the definition of high or low milk intake, was only 0.312 servings. Eighty-one $(26.6 \%)$ individuals in the low milk consumption groups reported no milk intake at all during the 3 days of diet recalls. Despite the many health advantages of consuming dairy products (57), intake by adults is low $(35,36,58)$, and as many as $75 \%$ of women fail to meet the recommendations for calcium intake (59). Diets of low-income women $(11,59,60)$ have been shown to be very low in dairy product consumption. There are also ethnic differences in consumption of milk; in this study, Hispanic women were more likely to be in 
one of the two high milk consumption groups than either African-American or white women; conversely, African-American women were more likely to be in either of the low milk consumption groups. This supports previous findings that Hispanics have better diets when compared with other ethnic groups $(61,62)$ and confirms other findings using data from these mothers (6). That the African-American women in the study consumed few dairy products is not surprising. Other studies have shown that these women report not consuming dairy products because of real or perceived lactose intolerance (63), lack of nutrition knowledge, the belief that they are not at risk for osteoporosis (64,65), or cultural preferences (66). African Americans had the highest percentage of participants in the low milk consumption groups, which is consistent with other studies $(20,35)$.

This study did not show the inverse relationship of milk intake and weight that has been shown by other cross-sectional studies that looked at dairy intake $(67,68)$, possibly because of the low number of servings of milk consumed. The risk of obesity in women consuming $3 \frac{1}{2}$ servings of dairy foods per day was $84 \%$ lower than in those consuming 1 serving per day (67). Others have failed to confirm this association $(69,70)$.

The two high milk groups, especially with low sweetened beverage consumption, showed increased nutrient intake, dietary adequacy, and consumption of more nutrient-dense foods. Women in the high milk consumption groups had considerably higher intakes of several key nutrients, including calcium, magnesium, and vitamin A, which are shortfall nutrients in the diets of adults (40). Both low sweetened beverage consumption groups had higher intakes of dietary fiber, which is also a shortfall nutrient (40). That the combination of high milk and low sweetened beverage consumption contributed to a positive nutrient intake suggests that it is the overall beverage pattern that is important.

Milk is not a good source of iron or folate (57). The fact that women in the high milk/low sweetened beverage consumption group had the highest intake of these nutrients may result from their higher intake of dark green and yellow vegetables and fruit, and suggests that their overall diet is better than women in the other beverage consumption groups. Both high milk consumption groups were associated with increased consumption of RTEC, suggesting that RTEC may be a way to increase milk consumption in Head Start mothers. RTECs are usually accompanied by milk and the overall impact on diet is positive, with increased intake of protein, calcium, and vitamins A and D (71). This may be one reason why women with higher milk consumption have higher nutrient intakes.

Total number of servings of beverages was not different among the beverage consumption groups. However, women in the high milk/low sweetened beverage group tended to make more healthful beverages choices, and consumed more servings of $100 \%$ fruit juice and water than women in the other beverage consumption groups. In the low sweetened beverage groups, 47 (8\%) drank no sweetened beverages and overall median consumption was $<1.5$ servings/day. It is difficult to make comparisons with sweetened beverage consumption of this population and other studies because of differences in age categories, the way data are presented, and how sweetened beverages are defined. However, if the servings in this study are converted to grams, the low milk/high sweetened beverage and high milk/high sweetened beverage consumed 694 $\mathrm{g}$ and $588 \mathrm{~g}$, respectively, which are higher than the reported values for women between 20 and 39 years of age or 40 to 59 years of age for regular carbonated drinks and regular fruit drinks/ades combined (20).

This study had several limitations. The cross-sectional study design does not provide the longitudinal data needed to determine if the increased energy intake associated with increased milk and sweetened beverage consumption would lead to weight gain over time. As with any cross-sectional study, no cause-and-effect relationships can be determined. In studies using 
24-hour recalls to assess dietary intake, reporting errors may have occurred. This population was relatively homogeneous for factors that typically are associated with underreporting: female (72), high BMI (73), low income (74,75), and low educational level (76). Energy intake was used as a covariate to compensate for underreporting of energy (77). A population from limited geographic areas was used; therefore, results may not be generalizable. Finally, because this was a secondary analysis of data, some information about potentially confounding information was not available; this includes physical activity levels, smoking, alcohol intake, and lactose intolerance. That these potential confounders were not included could limit the generalizability of the data.

\section{CONCLUSIONS}

In a multiethnic, low-income population of women consumption of high milk/low sweetened beverages was associated with improved nutrient intake and more healthful food choices, including fruit, dark green and deep yellow vegetables, and RTEC. Although nutrient intake and dietary adequacy were improved with increased consumption of milk, overall milk intake and MAR were generally low in these women, indicating the need for improved diet in women in all four of the beverage consumption groups. Culturally appropriate nutrition education addressing specific barriers to consuming a healthful diet, including increasing milk consumption and decreasing sweetened beverage consumption, should be designed and consumption of nutrient-dense foods should be encouraged.

\section{Acknowledgments}

This research was supported by funds from the National Cancer Institute grant no. RO1 CA102671. Partial support was received from the National Dairy Council and US Department of Agriculture Hatch Projects 940-36-3104 Project \#93673 and LAB 93676 \#0199070. This work is a publication of the United States Department of Agriculture (USDA/ ARS) Children's Nutrition Research Center, Department of Pediatrics, Baylor College of Medicine in Houston, Texas and was also funded in part with federal funds from the USDA/ARS under Cooperative Agreement no. 58-6250-6-003.

The authors thank Michelle Feese and Sheryl O. Hughes, Project Coordinators for the sites, and Sandra Lopez, the research assistant. All were instrumental in the collection of these data. We also thank Bee Wong for her help with the literature and Pamelia Harris for secretarial help. We also extend a special thanks to the children and parents of Head Start who participated in this study.

\section{References}

1. US Department of Health and Human Services. Improving Head Start. US Department of Health and Human Services; [Accessed June 27, 2008]. Web sitehttp://www.hhs.gov/headstart. Updated December 31, 2003

2. Cullen KW, Baranowski T, Klesges LM, Watson K, Sherwood NE, Story M, Zakeri I, LeachmanSlawson D, Pratt C. Anthropomorphic, parental, and psychosocial correlates of dietary intake of African American girls. Obesity 2004;12(suppl):20s-31s.

3. Johnson SL, Birch LL. Parents' and children's adiposity and eating style. Pediatrics 1994;94:653-661. [PubMed: 7936891]

4. Hood MY, Moore LL, Sundarajan-Ramamurti A, Singer M, Cupples LA, Ellison RC. Parental eating attitudes and the development of obesity in children. The Framingham Children's Study. Int J Obes 2000;24:1319-1325.

5. Tibbs S, Haire-Joshu D, Schechtman KB, Brownson RC, Nanney MS, Houston C, Auslander W. The relationship between parental modeling, eating patterns, and dietary intake among African American parents. J Am Diet Assoc 2001;101:535-541. [PubMed: 11374346]

6. Hoerr SL, Tsuei E, Liu Y, Franklin FA, Nicklas TA. Diet quality varies by race/ethnicity of Head Start mothers. J Am Diet Assoc 2008;108:651-659. [PubMed: 18375222] 
7. Hoerr SL, Horodynski MA, Lee SY, Henry M. Predictors of nutritional adequacy in mother-toddler dyads from rural families with limited incomes. J Am Diet Assoc 2006;106:1766-1773. [PubMed: 17081827]

8. Tarasuk VA. Household food insecurity with hunger is associated with woman's food intakes, health, and household circumstances. J Nutr 2001;131:2670-2676. [PubMed: 11584089]

9. Rose D. Economic determinants and dietary consequences of food insecurity in the United States. J Nutr 1999;129(suppl):517S-520S. [PubMed: 10064321]

10. Cristofar SP, Basiotis PP. Dietary intakes and selected characteristics of women ages 19-50 years and their children ages 1-5 years by reported perception of food sufficiency. J Nutr Educ 1992;24:5358 .

11. Dixon LB, Winkleby MA, Radimer KL. Dietary intakes and serum nutrients differ between adults from food-insufficient and food-sufficient families: Third National Health and Nutrition Examination Survey, 1988-1994. J Nutr 2001;131:1232-1246. [PubMed: 11285332]

12. Paeratakul S, Lovejoy JC, Ryan DH, Bray GA. The relation of gender, race and socioeconomic status to obesity and obesity comorbidities in a sample of US adults. Int J Obes 2002;26:1205-1210.

13. Stuff JE, Casey PH, Szeto KL, Gossett JM, Robbins JM, Simpson PM, Connell C, Bogle ML. Household food insecurity is associated with adult health status. J Nutr 2004;134:2330-2335. [PubMed: 15333724]

14. Vozoris NT, Tarasuk VS. Household food insufficiency is associated with poorer health. J Nutr 2003;133:120-126. [PubMed: 12514278]

15. Scheier LM. What is the hunger-obesity paradox? J Am Diet Assoc 2005;105:883-886. [PubMed: 15942535]

16. Ramsey PW, Glenn LL. Obesity and health status in rural, urban, and suburban Southern women. South Med J 2002;95:666-671. [PubMed: 12144068]

17. Townsend MS, Peerson J, Love B, Achterberg C, Murphy SP. Food insecurity is positively related to overweight in women. J Nutr 2001;131:1738-1745. [PubMed: 11385061]

18. Ogden CL, Carroll MD, Curtin LR, McDowell MA, Tabak CJ, Flegal KM. Prevalence of overweight and obesity in the United States, 1999-2004. JAMA 2006;295:1549-1555. [PubMed: 16595758]

19. Storey ML, Forshee RA, Anderson PA. Beverage consumption in the US population. J Am Diet Assoc 2006;106:1992-2000. [PubMed: 17126630]

20. Nielsen SJ, Popkin BM. Changes in beverage intake between 1977 and 2001. Am J Prev Med 2004;27:205-210. [PubMed: 15450632]

21. Malik VS, Schulze MB, Hu FB. Intake of sugar-sweetened beverages and weight gain: A systematic review. Am J Clin Nutr 2006;84:274-288. [PubMed: 16895873]

22. Block G. Foods contributing to energy intake in the US: Data from NHANES III and NHANES 19992000. J Food Compost Anal 2004;17:439-447.

23. Ballew C, Kuester S, Gillespie C. Beverage choices affect adequacy of children's nutrient intakes. Arch Pediatr Adolesc Med 2000;154:1148-1152. [PubMed: 11074858]

24. Kant AK. Consumption of energy-dense, nutrient-poor foods by adult Americans: Nutritional and health implications. The third National Health and Nutrition Examination Survey, 1988-1994. Am J Clin Nutr 2000;72:929-936. [PubMed: 11010933]

25. Mrdjenovic G, Levitsky DA. Nutritional and energetic consequences of sweetened drink consumption in 6- to 13-year-old children. J Pediatr 2003;142:604-610. [PubMed: 12838186]

26. Bowman SA. Beverage choices of young females: Changes and impact on nutrient intakes. J Am Diet Assoc 2002;102:1234-1239. [PubMed: 12792618]

27. Harnack L, Stang J, Story M. Soft drink consumption among US children and adolescents: Nutritional consequences. J Am Diet Assoc 1999;99:436-441. [PubMed: 10207395]

28. Forshee RA, Storey ML. Demographics, not beverage consumption, is associated with diet quality. Int J Food Sci Nutr 2006;57:494-511. [PubMed: 17162328]

29. Storey ML, Forshee RA, Anderson PA. Associations of adequate intake of calcium with diet, beverage consumption, and demographic characteristics among children and adolescents. J Am Coll Nutr 2004;23:18-33. [PubMed: 14963050] 
30. Schulze MB, Manson JE, Ludwig DS, Colditz GA, Stampfer MJ, Willett WC, Hu FB. Sugarsweetened beverages, weight gain, and incidence of type 2 diabetes in young and middle-aged women. JAMA 2004;292:927-934. [PubMed: 15328324]

31. Bes-Rastrollo M, Sánchez-Villegas A, Gómez-Gracia E, Martínez JA, Pajares RM, MartínezGonzález MA. Predictors of weight gain in a Mediterranean cohort: The Seguimiento Universidad de Navarra Study 1. Am J Clin Nutr 2006;83:362-370. [PubMed: 16469996]

32. Bachman CM, Baranowski T, Nicklas TA. Is there an association between sweetened beverages and adiposity? Nutr Rev 2006;64:153-174. [PubMed: 16673752]

33. Sun SZ, Empie MW. Lack of findings for the association between obesity risk and usual sugarsweetened beverage consumption in adults-A primary analysis of databases of CSFII-1989-1991, CSFII-1994-1998, NHANES III, and combined NHANES 1999-2002. Food Chem Toxicol 2007;45:1523-1536. [PubMed: 17383789]

34. Johnson L, Mander AP, Jones LR, Emmett PM, Jebb SA. Is sugar-sweetened beverage consumption associated with increased fatness in children? Nutrition 2007;23:557-563. [PubMed: 17616342]

35. Fulgoni V, Nicholls J, Reed A, Buckley R, Kafer K, Huth P, DiRienzo D, Miller GD. Dairy consumption and related nutrient intake in African-American adults and children in the United States: Continuing survey of food intakes by individuals 1994-1996, 1998, and the National Health and Nutrition Examination Survey 1999-2000. J Am Diet Assoc 2007;107:256-264. [PubMed: 17258962]

36. Ranganathan R, Nicklas TA, Yang SJ, Berenson GS. The nutritional impact of dairy product consumption on dietary intakes of adults (1995-1996): The Bogalusa Heart Study. J Am Diet Assoc 2005;105:1391-400. [PubMed: 16129080]

37. Weinberg LG, Berner LA, Groves JE. Nutrient contributions of dairy foods in the United States food supply. J Am Diet Assoc 2004;104:895-902. [PubMed: 15175587]

38. Barr SI, McCarron DA, Heaney RP, Dawson-Hughes B, Berga SL, Stern JS, Oparil S. Effects of increased consumption of fluid milk on energy and nutrient intake, body weight, and cardiovascular risk factors in healthy older adults. J Am Diet Assoc 2000;100:810-817. [PubMed: 10916520]

39. Foote JA, Murphy SP, Wilkens LR, Basiotis PP, Carlson A. Dietary variant increases the probability of nutrient adequacy among adults. J Nutr 2004;134:1779-1785. [PubMed: 15226469]

40. US Department of Health and Human Services, US Department of Agriculture. Executive Summary. US Department of Health and Human Services, US Department of Agriculture; [Accessed June 27, 2008]. Dietary Guidelines for Americans 2005. Web sitehttp://www.health.gov/dietaryguidelines/dga2005/document/html/executivesummary.htm. Updated May 16, 2008

41. Lin YC, Lyle RM, McCabe LD, McCabe GP, Weaver CM, Teegarden D. Dairy calcium is related to changes in body composition during a two-year exercise intervention in young women. J Am Coll Nutr 2000;19:754-760. [PubMed: 11194528]

42. Davies KM, Heaney RP, Recker RR, Lappe JM, Barger-Lux MJ, Rafferty K, Hinders S. Calcium intake and body weight. J Clin Endocrinol Metab 2000;85:4635-4638. [PubMed: 11134120]

43. Mirmiran P, Esmaillzadeh A, Azizi F. Dairy consumption and body mass index: An inverse relationship. Int J Obes (Lond) 2005;29:115-121. [PubMed: 15534616]

44. Zemel MB, Richards J, Milstead A, Campbell P. Effects of calcium and dairy on body composition and weight loss in African-American adults. Obesity 2005;13:1218-1225.

45. Huang TT, Roberts SB, Howarth NC, McCrory MA. Effect of screening out implausible energy intake reports on relationships between diet and BMI. Obesity 2005;13:1205-1217.

46. Conway JM, Ingwersen LA, Vinyard BT, Moshfegh AJ. Effectiveness of the US Department of Agriculture 5-step multiple pass method in assessing food intake in obese and non-obese women. Am J Clin Nutr 2003;77:1171-1178. [PubMed: 12716668]

47. Posner BM, Smigleski C, Duggal A, Morgan JL, Cobb J, Cupples LA. Validation of two-dimensional models for estimation of portion size in nutrition research. J Am Diet Assoc 1992;92:738-741. [PubMed: 1607574]

48. Lohman, TG.; Roche, AF.; Martorell, R. Anthropometric Standardization Reference Manual. Champaign, IL: Human Kinetics Books; 1988. 
49. Nutrient Data Laboratory, Beltsville Human Nutrition Research Center, Agricultural Research Service, US Department of Agriculture. USDA Database for the Added Sugars Content of Selected Foods (Release 1). [Accessed June 27, 2008].

http://www.nal.usda.gov/fnic/foodcomp/Data/add_sug/addsug01.pdf. Updated February, 2006

50. Krebs-Smith SM, Clark LD. Validation of a nutrient adequacy score for use with women and children. J Am Diet Assoc 1989;89:775-783. [PubMed: 2723299]

51. US Department of Agriculture. MyPyramid.gov. Steps to a Healthier You. [Accessed June 28, 2008]. MyPyramid Web site. http://www.mypyramid.gov

52. Schakel SF. Maintaining a nutrient database in a changing marketplace: Keeping pace with changing food products-A research perspective. J Food Compost Anal 2001;14:315-322.

53. National Institutes of Health, National Heart Lung and Blood Institute. Clinical Guidelines on the Identification, Evaluation, and Treatment of Overweight and Obesity in Adults: The Evidence Report. 1998 [Accessed June 27, 2008]. NIH Publication No. 98-4083.

http://www.nhlbi.nih.gov/guidelines/obesity/ob_gdlns.pdf. Published September 1998

54. Duffey KJ, Popkin BM. Adults with healthier dietary patterns have healthier beverage patterns. J Nutr 2006;136:2901-2907. [PubMed: 17056820]

55. Ver Ploeg M, Mancino L, Lin BH, Wang CY. The vanishing weight gap: Trends in obesity among adult food stamp participants (US) (1976-2002). Econ Hum Biol 2007;5:20-36. [PubMed: 17113841]

56. Kendall A, Olson CM, Frongillo EA Jr. Relationship of hunger and food insecurity to food availability and consumption. J Am Diet Assoc 1996;96:1019-1024. [PubMed: 8841164]

57. Huth PJ, DiRienzo DB, Miller GD. Major scientific advances with dairy foods in nutrition and health. J Dairy Sci 2006;89:1207-1221. [PubMed: 16537954]

58. Deshmukh-Taskar P, Nicklas TA, Yang SJ, Berenson GS. Does food group consumption vary by differences in socioeconomic, demographic, and lifestyle factors in young adults? The Bogalusa Heart Study. J Am Diet Assoc 2007;107:223-223. [PubMed: 17258958]

59. Arab L, Carriquiry A, Steck-Scott S, Gaudet MM. Ethnic differences in the nutrient intake adequacy of premenopausal US women: Results from the Third National Health Examination Survey. J Am Diet Assoc 2003;103:1008-1014. [PubMed: 12891149]

60. Champagne CM, Bogle ML, McGee BB, Yadrick K, Allen HR, Kramer TR, Simpson P, Gossett J, Weber J. Lower Mississippi Delta Nutrition Intervention Research Initiative. Dietary intake in the lower Mississippi delta region: Results from the Foods of our Delta Study. J Am Diet Assoc 2004;104:199-207. [PubMed: 14760567]

61. Dixon LB, Sundquist J, Winkleby M. Differences in energy, nutrient and food intakes in a US sample of Mexican American women and men: Findings from the third National Health and Nutrition Examination Survey, 1988-94. Am J Epidemiol 2000;152:548-557. [PubMed: 10997545]

62. Neuhauser ML, Thompson B, Coronado GD, Solomon CC. Higher fat intake and lower fruit and vegetable intakes with greater acculturation among Mexican Americans living in Washington State. J Am Diet Assoc 2004;104:51-57. [PubMed: 14702584]

63. Monroe, PA.; O’Neil, CE.; Tiller, VV.; Smith, J. Food Assistance Needs of the South's Vulnerable Populations. Southern Rural Development Center; [Accessed June 27, 2008]. The Challenge of compliance: Food security in rural households affected by welfare reform. http://eric.ed.gov/ERICDocs/data/ericdocs2sq1/content_storage_01/0000019b/80/29/d0/be.pdf. Published September 1998

64. Buchowski MS, Semenya J, Johnson AO. Dietary calcium intake in lactose maldigesting intolerant and tolerant African-American women. J Am Coll Nutr 2002;21:47-54. [PubMed: 11838887]

65. Geller SE, Derman R. Knowledge, beliefs, and risk factors for osteoporosis among African-American and Hispanic women. J Natl Med Assoc 2001;93:13-21. [PubMed: 12653376]

66. Lara-Smalling AA, Shelton AJ, Douglas TC, Rianon NJ. Osteoporosis among perimenopausal African-American women: The relationship between sources of information and levels of knowledge about osteoporosis. J Natl Black Nurses Assoc 2004;15:40-47. [PubMed: 15853285]

67. Wooten WJ, Price W. Consensus report of the National Medical Association. The role of dairy and dairy nutrients in the diet of African Americans. J Natl Med Assoc 2004;96(suppl):5S-31S. [PubMed: 15624290] 
68. Loos RJ, Rankinen T, Leon AS, Skinner JS, Wilmore JH, Rao DC, Bouchard C. Calcium intake is associated with adiposity in Black and White men and White women of the HERITAGE Family Study. J Nutr 2004;134:1772-1778. [PubMed: 15226468]

69. Brooks BM, Rajeshwari R, Nicklas TA, Yang SJ, Berenson GS. Association of calcium intake, dairy product consumption with overweight status in young adults (1995-1996): The Bogalusa Heart Study. J Am Coll Nutr 2006;25:523-532. [PubMed: 17229900]

70. Venti CA, Tataranni PA, Salbe AD. Lack of relationship between calcium intake and body size in an obesity-prone population. J Am Diet Assoc 2005;105:1401-1407. [PubMed: 16129081]

71. Song WO, Chun OK, Kerver J, Cho S, Chung CE, Chung S-J. Ready-to-eat breakfast cereal consumption enhances milk and calcium intake in the US population. J Am Diet Assoc 2006;106:1783-1789. [PubMed: 17081829]

72. Yannakoulia M, Panagiotakos DB, Pitsavos C, Bathrellou E, Chrysohoou C, Skoumas Y, Stefanadis C. Low energy reporting related to lifestyle, clinical, and psychosocial factors in a randomly selected population sample of Greek adults: The ATTICA Study. J Am Coll Nutr 2007;26:327-333. [PubMed: 17906184]

73. Bailey RL, Mitchell DC, Miller C, Smicklas-Wright H. Assessing the effect of underreporting energy intake on dietary patterns and weight status. J Am Diet Assoc 2007;107:64-71. [PubMed: 17197273]

74. Stallone DD, Brunner EJ, Bingham SA, Marmot MG. Dietary assessment in Whitehall II: The influence of reporting bias on apparent socioeconomic variation in nutrient intakes. Eur J Clin Nutr 1997;51:815-825. [PubMed: 9426356]

75. Devaney, B.; Kim, M.; Carriquiry, A.; Camano-Garcia, G. Mathematica Policy Research, Inc. Assessing the nutrient intakes of vulnerable subgroups. US Department of Agriculture, Economic Research Service; [Accessed August 2, 2007]. http://www.ers.usda.gov/Publications/CCR11/ccr11.pdf. Updated October 4, 2005

76. Johnson RK, Soultanakis RP, Matthews DE. Literacy and body fatness are associated with underreporting of energy intake in US low-income women using the multiple-pass 24-hour recall: A doubly labeled water study. J Am Diet Assoc 1998;98:1136-1140. [PubMed: 9787719]

77. Flegal KM. Evaluating epidemiologic evidence of the effects of food and nutrient exposures. Am J Clin Nutr 1999;69(suppl):1339S-1344S. [PubMed: 10359234] 
O'NEIL et al.

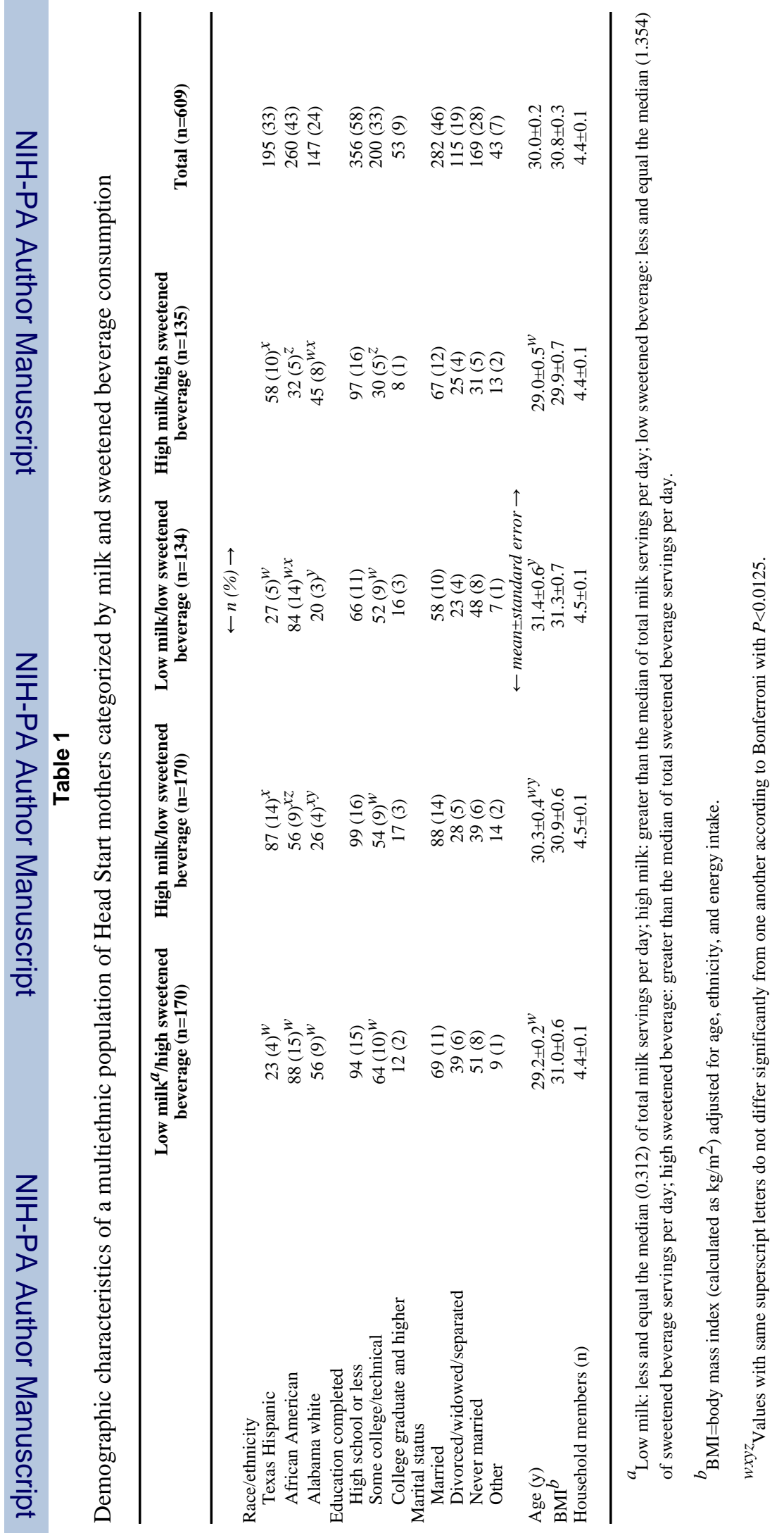

J Am Diet Assoc. Author manuscript; available in PMC 2009 December 10. 
Table 2

Nutritional adequacy and intake of energy and nutrients by milk and sweetened beverage consumption groups of a multiethnic population of Head Start mothers

\begin{tabular}{|c|c|c|c|c|}
\hline & $\begin{array}{c}\text { Low milk }{ }^{a} / \text { high sweetened } \\
\text { beverage }(n=170)\end{array}$ & $\begin{array}{l}\text { High milk/low sweetened } \\
\text { beverage }(n=170)\end{array}$ & $\begin{array}{l}\text { Low milk/low sweetened } \\
\text { beverage }(n=134)\end{array}$ & $\begin{array}{l}\text { High milk/high sweetened } \\
\text { beverage }(n=135)\end{array}$ \\
\hline & \multicolumn{4}{|c|}{$\leftarrow$ least-square mean \pm standard error $\rightarrow$} \\
\hline Energy $(\mathrm{kcal})^{b}$ & $1,820 \pm 42.1^{w}$ & $1,667 \pm 42.0^{x}$ & $1,386 \pm 48.5^{y}$ & $1,948 \pm 45.9^{w}$ \\
\hline $\operatorname{MAR}^{c}$ & $58.4 \pm 0.8^{w}$ & $71.8 \pm 0.8^{x}$ & $62.5 \pm 1.0^{y}$ & $64.8 \pm 0.9^{y}$ \\
\hline Vitamin $\mathrm{A}^{d}(\mu \mathrm{g})$ & $545 \pm 55.5^{w}$ & $1017 \pm 55^{x}$ & $675 \pm 65.7^{w}$ & $706 \pm 61.6^{w}$ \\
\hline Vitamin $\mathrm{D}^{d}(\mu \mathrm{g})$ & $2.4 \pm 0.3^{w}$ & $5.1 \pm 0.3^{x}$ & $2.8 \pm 0.3^{w}$ & $4.0 \pm 0.3^{z}$ \\
\hline Vitamin $C^{d}(\mathrm{mg})$ & $61.0 \pm 4.3^{w}$ & $92.0 \pm 4.2^{x}$ & $75.0 \pm 5^{w x}$ & $71.0 \pm 4.7^{w}$ \\
\hline $\operatorname{Vitamin~}^{d}(\alpha$-tocopherol) & $4.8 \pm 0.2^{w}$ & $6.0 \pm 0.2^{x y}$ & $6.0 \pm 0.2^{y}$ & $4.9 \pm 0.2^{w x}$ \\
\hline Vitamin B-6 $6^{d}(\mathrm{mg})$ & $1.2 \pm 0.0^{w}$ & $1.8 \pm 0.0^{x}$ & $1.5 \pm 0.0^{y}$ & $1.5 \pm 0.0^{y}$ \\
\hline $\operatorname{Niacin}^{d}(\mathrm{mg})$ & $16.5 \pm 0.4^{w}$ & $19.5 \pm 0.4^{x y}$ & $18.2 \pm 0.5^{y}$ & $17.8 \pm 0.4^{w x}$ \\
\hline Riboflavin $^{d}(\mathrm{mg})$ & $1.2 \pm 0.0^{w}$ & $2.0 \pm 0.0^{x}$ & $1.0 \pm 0.0^{y}$ & $1.6 \pm 0.0^{z}$ \\
\hline Thiamin $^{d}(\mathrm{mg})$ & $1.0 \pm 0.0^{w}$ & $1.5 \pm 0.0^{x}$ & $1.3 \pm 0.0^{y}$ & $1.3 \pm 0.0^{y}$ \\
\hline Folate $^{d}(\mathrm{mg})$ & $307 \pm 10.6^{w}$ & $434 \pm 10.5^{x}$ & $361 \pm 12.5^{y}$ & $376 \pm 11.7^{y}$ \\
\hline Phosphorus $(\mathrm{mg})$ & $912 \pm 16.1^{w}$ & $1,148 \pm 16.0^{x}$ & $1,040 \pm 19.1^{y}$ & $1,015 \pm 17.9^{y}$ \\
\hline Sodium $^{d}(\mathrm{mg})$ & $2,905 \pm 56.0$ & $2,905 \pm 55.5$ & $3,072 \pm 66.3$ & $2,859 \pm 62.1$ \\
\hline Calcium $^{d}(\mathrm{mg})$ & $494 \pm 15.8^{w}$ & $758 \pm 15.7^{x}$ & $588 \pm 18.7^{y}$ & $657 \pm 17.5^{z}$ \\
\hline $\operatorname{Iron}^{d}(\mathrm{mg})$ & $10.7 \pm 0.3^{w}$ & $14.4 \pm 0.3^{x}$ & $11.8 \pm 0.3^{y}$ & $12.5 \pm 0.3^{y}$ \\
\hline Magnesium $^{d}(\mathrm{mg})$ & $176 \pm 3.7^{w}$ & $232 \pm 3.7^{x}$ & $215 \pm 4.4^{y}$ & $195 \pm 4.1^{z}$ \\
\hline Potassium $^{d}(\mathrm{mg})$ & $1,684 \pm 35.6^{w}$ & $2,281 \pm 35.3^{x}$ & $1,950 \pm 42.2^{y}$ & $1,887 \pm 39.5^{y}$ \\
\hline $\operatorname{Zinc}^{d}(\mathrm{mg})$ & $8.0 \pm 0.2^{w}$ & $9.3 \pm 0.2^{x}$ & $8.7 \pm 0.2^{w x}$ & $8.9 \pm 0.2^{x}$ \\
\hline Protein $^{d}(\mathrm{~g})$ & $62.0 \pm 1.1^{w}$ & $70.4 \pm 1.1^{x}$ & $67.9 \pm 1.3^{x}$ & $62.5 \pm 1.2^{w}$ \\
\hline Fat, total ${ }^{d}(\mathrm{~g})$ & $65.7 \pm 1.0^{w}$ & $66.4 \pm 1^{w}$ & $72.0 \pm 1.2^{y}$ & $61.5 \pm 1.1^{z}$ \\
\hline $\operatorname{SFA}^{e}(\mathrm{~g})$ & $22.0 \pm 0.5^{w z}$ & $23.0 \pm 0.4^{w x}$ & $24.0 \pm 0.5^{x y}$ & $21.0 \pm 0.5^{z}$ \\
\hline $\operatorname{MUFA}^{f}(\mathrm{~g})$ & $25.2 \pm 0.4^{w}$ & $25.0 \pm 0.4^{w}$ & $28.0 \pm 0.5^{y}$ & $22.7 \pm 0.5^{z}$ \\
\hline PUFA $^{g}(\mathrm{~g})$ & $13.0 \pm 0.4^{w}$ & $12.7 \pm 0.4^{w}$ & $14.7 \pm 0.4^{x}$ & $12.4 \pm 0.4^{w}$ \\
\hline $\mathrm{n}-3$ fatty acid (mg) & $1.2 \pm 0.1^{w}$ & $1.3 \pm 0.1^{w x}$ & $1.5 \pm 0.1^{x}$ & $1.3 \pm 0.1^{w x}$ \\
\hline Trans fat $(\mathrm{g})$ & $4.8 \pm 0.2$ & $4.0 \pm 0.2$ & $5.0 \pm 0.2$ & $4.3 \pm 0.2$ \\
\hline$\%$ kcal fat ${ }^{b}$ & $34.0 \pm 0.5$ & $33.8 \pm 0.5$ & $36.0 \pm 0.6$ & $33.0 \pm 0.6$ \\
\hline$\%$ kcal SFA ${ }^{b}$ & $11.0 \pm 0.2$ & $11.8 \pm 0.2$ & $12.0 \pm 0.3$ & $11.4 \pm 0.2$ \\
\hline Cholesterol $^{d}(\mathrm{mg})$ & $253 \pm 10.7^{w x}$ & $281 \pm 10.6^{w}$ & $275 \pm 12.7^{w x}$ & $236 \pm 11.9^{x}$ \\
\hline Carbohydrate $^{d}(\mathrm{~g})$ & $219 \pm 2.8^{w z}$ & $210 \pm 2.7^{w}$ & $199 \pm 3.3^{x}$ & $229 \pm 3.1^{z}$ \\
\hline Dietary fiber $^{d}(\mathrm{~g})$ & $11.9 \pm 0.4^{w}$ & $16.0 \pm 0.4^{x}$ & $15.0 \pm 0.5^{x}$ & $13.1 \pm 0.4^{w}$ \\
\hline Total sugars $^{d}(\mathrm{~g})$ & $110 \pm 2.4^{w}$ & $88.9 \pm 2.4^{x}$ & $76.2 \pm 2.8^{y}$ & $112 \pm 2.6^{w}$ \\
\hline$\%$ kcal sugars $b^{b}$ & $26.9 \pm 0.6$ & $21.6 \pm 0.6$ & $18.8 \pm 0.7$ & $26 \pm 0.7$ \\
\hline Added sugar ${ }^{d}(\mathrm{~g})$ & $94.3 \pm 2.2^{w}$ & $48.0 \pm 2.2^{x}$ & $53.0 \pm 2.6^{x}$ & $86.3 \pm 2.4^{w}$ \\
\hline$\%$ kcal added sugars $b$ & $23.0 \pm 0.6$ & $11.3 \pm 0.6$ & $13.0 \pm 0.7$ & $20.4 \pm 0.6$ \\
\hline
\end{tabular}

${ }^{a}$ Low milk=less and equal the median (0.312) of total milk servings per day; high milk: greater than the median of total milk servings per day; low sweetened beverage=less and equal the median (1.354) of sweetened beverage servings per day; high sweetened beverage=greater than the median of total sweetened beverage servings per day.

${ }^{b}$ Adjusted for age and ethnicity only.

${ }^{c}$ MAR=mean adequacy ratios were the \%Recommended Daily Allowance for each of eight nutrients (dietary fiber, vitamins A and C, folate, calcium, iron, zinc, and potassium) but truncated at 100 prior to averaging.

${ }^{d}$ Adjusted for age, ethnicity, and energy intake.

$e_{\mathrm{SFA}=\text { saturated fatty acid. }}$

$f_{\text {MUFA }=\text { monounsaturated fatty acid. }}$

$g_{\text {PUFA=polyunsaturated fatty acid. }}$

${ }^{w x y z}$ Means with the same superscript letters do not differ significantly from one another according to Bonferroni with $P<0.0125$. 
Table 3

Mean consumption of food groups ${ }^{a}$ by milk and sweetened beverage consumption groups of a multiethnic population of Head Start mothers

\begin{tabular}{|c|c|c|c|c|}
\hline Food groups & $\begin{array}{l}\text { Low milk }{ }^{b} / \text { high sweetened } \\
\text { beverage }(n=170)\end{array}$ & $\begin{array}{c}\text { High milk/low sweetened } \\
\text { beverage }(\mathbf{n}=170)\end{array}$ & $\begin{array}{c}\text { Low milk/low sweetened } \\
\text { beverage }(\mathrm{n}=134)\end{array}$ & $\begin{array}{l}\text { High milk/high sweetened } \\
\text { beverage }(\mathrm{n}=135)\end{array}$ \\
\hline & \multicolumn{4}{|c|}{$\leftarrow$ least-square mean \pm standard error ${ }^{c} \rightarrow$} \\
\hline $\operatorname{Grain}^{d}$ & $5.31 \pm 0.12$ & $5.61 \pm 0.12$ & $5.69 \pm 0.14$ & $5.73 \pm 0.13$ \\
\hline Whole grains & $0.89 \pm 0.11^{w}$ & $1.30 \pm 0.10^{x}$ & $1.23 \pm 0.13^{w x}$ & $1.22 \pm 0.12^{w x}$ \\
\hline Breads and pastas & $4.53 \pm 0.13$ & $4.33 \pm 0.13$ & $4.8 \pm 0.15$ & $4.52 \pm 0.14$ \\
\hline Ready-to-eat cereals & $0.08 \pm 0.04^{w}$ & $0.7 \pm 0.04^{x}$ & $0.13 \pm 0.05^{w}$ & $0.49 \pm 0.05^{y}$ \\
\hline Cakes, cookies, pies, and pastries & $0.41 \pm 0.05$ & $0.37 \pm 0.05$ & $0.48 \pm 0.05$ & $0.38 \pm 0.05$ \\
\hline Salty snacks & $0.28 \pm 0.03^{w x}$ & $0.21 \pm 0.03^{w}$ & $0.28 \pm 0.04^{w x}$ & $0.34 \pm 0.04^{x}$ \\
\hline Fruit & $0.42 \pm 0.06^{w}$ & $0.83 \pm 0.06^{x}$ & $0.60 \pm 0.07^{w}$ & $0.45 \pm 0.07^{w}$ \\
\hline Vegetables $^{e}$ & $2.28 \pm 0.10$ & $2.61 \pm 0.10$ & $2.52 \pm 0.12$ & $2.43 \pm 0.11$ \\
\hline Dark green and deep yellow & $0.19 \pm 0.03^{w}$ & $0.36 \pm 0.03^{x}$ & $0.21 \pm 0.04^{w}$ & $0.21 \pm 0.04^{w}$ \\
\hline Tomatoes & $0.45 \pm 0.04$ & $0.52 \pm 0.04$ & $0.57 \pm 0.05$ & $0.58 \pm 0.05$ \\
\hline Starchy & $0.12 \pm 0.02$ & $0.17 \pm 0.02$ & $0.11 \pm 0.03$ & $0.17 \pm 0.02$ \\
\hline Legumes & $0.29 \pm 0.04$ & $0.40 \pm 0.04$ & $0.45 \pm 0.05$ & $0.31 \pm 0.05$ \\
\hline Fried vegetables & $0.39 \pm 0.04$ & $0.28 \pm 0.04$ & $0.35 \pm 0.04$ & $0.27 \pm 0.04$ \\
\hline Potatoes & $0.36 \pm 0.03^{w}$ & $0.24 \pm 0.03^{w x}$ & $0.33 \pm 0.04^{w x}$ & $0.23 \pm 0.04^{x}$ \\
\hline Other & $0.84 \pm 0.05$ & $0.90 \pm 0.05$ & $0.83 \pm 0.07$ & $0.90 \pm 0.06$ \\
\hline Dairy (includes fluid milk) & $0.72 \pm 0.07^{w}$ & $1.65 \pm 0.07^{x}$ & $0.96 \pm 0.08^{w y}$ & $1.22 \pm 0.07^{y}$ \\
\hline Cheese & $0.50 \pm 0.06$ & $0.50 \pm 0.06$ & $0.63 \pm 0.07$ & $0.40 \pm 0.07$ \\
\hline Dessert & $0.09 \pm 0.02$ & $0.12 \pm 0.02$ & $0.14 \pm 0.03$ & $0.08 \pm 0.03$ \\
\hline Meat & $5.01 \pm 0.18^{w}$ & $4.86 \pm 0.18^{w x}$ & $5.43 \pm 0.21^{w}$ & $4.20 \pm 0.20^{x}$ \\
\hline Red & $1.20 \pm 0.09$ & $1.11 \pm 0.09$ & $1.14 \pm 0.11$ & $1.29 \pm 0.10$ \\
\hline Pork & $0.70 \pm 0.08$ & $0.60 \pm 0.08$ & $0.64 \pm 0.09$ & $0.54 \pm 0.09$ \\
\hline Luncheon & $0.82 \pm 0.07^{w y}$ & $0.51 \pm 0.07^{x}$ & $0.70 \pm 0.08^{x y}$ & $0.52 \pm 0.07^{x}$ \\
\hline Poultry & $1.29 \pm 0.13$ & $1.40 \pm 0.12$ & $1.52 \pm 0.15$ & $1.02 \pm 0.14$ \\
\hline Fish & $0.51 \pm 0.1$ & $0.57 \pm 0.10$ & $0.58 \pm 0.12$ & $0.44 \pm 0.11$ \\
\hline Alternatives $f$ & $0.48 \pm 0.07^{w z}$ & $0.67 \pm 0.07^{w y}$ & $0.85 \pm 0.08^{y}$ & $0.40 \pm 0.08^{z}$ \\
\hline Beverages & $5.32 \pm 0.20$ & $5.80 \pm 0.20$ & $5.49 \pm 0.24$ & $5.40 \pm 0.23$ \\
\hline $100 \%$ fruit juice & $0.43 \pm 0.08^{w y}$ & $1.03 \pm 0.08^{x}$ & $0.73 \pm 0.09^{x y}$ & $0.45 \pm 0.09^{w y}$ \\
\hline Milk & $0.13 \pm 0.04^{w}$ & $1.02 \pm 0.04^{x}$ & $0.19 \pm 0.04^{w}$ & $0.74 \pm 0.04^{y}$ \\
\hline Sweetened beverages & $2.92 \pm 0.07^{w}$ & $0.67 \pm 0.07^{x}$ & $0.88 \pm 0.09^{x}$ & $2.43 \pm 0.08^{y}$ \\
\hline Noncaloric beverages & $0.44 \pm 0.08^{w}$ & $0.75 \pm 0.08^{x}$ & $0.98 \pm 0.10^{x}$ & $0.37 \pm 0.09^{w}$ \\
\hline Water & $1.31 \pm 0.19^{w}$ & $2.27 \pm 0.19^{x}$ & $2.53 \pm 0.22^{x}$ & $1.36 \pm 0.21^{w}$ \\
\hline
\end{tabular}

${ }^{a}$ Food servings are based on the Nutrient Data System for Research recommended serving sizes.

${ }^{b}$ Low milk=less and equal the median (0.312) of total milk servings per day; high milk=greater than the median of total milk servings per day; low sweetened beverage=less and equal the median (1.354) of sweetened beverage servings per day; high sweetened beverage=greater than the median of total sweetened beverage servings per day.

${ }^{c}$ Adjusted for age, ethnicity, and energy intake.

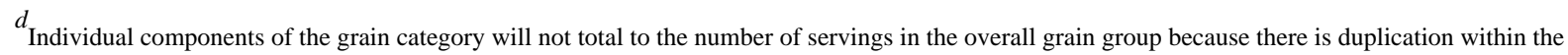
groups; eg, ready-to-eat cereals that are whole grains would have been counted in whole grains and in the ready-to-eat cereal group.

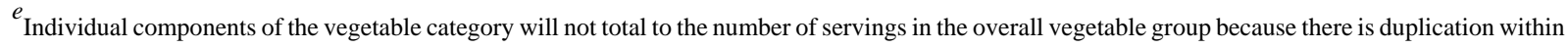
the groups; eg, fried potatoes presented as a group here are also included in the fried vegetable group.

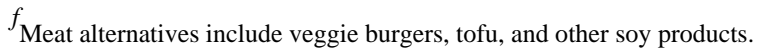

${ }^{w x y z}$ Means with the same superscript letters do not differ significantly from one another according to Bonferroni with $P<0.0125$. 